\title{
AUTRICHE
}

\section{LE COMTE DE FALKENHAYN ${ }^{1}$.}

Le comte Franz de Falkenhayn, président de la Croix-Rouge autrichienne, dont nous annoncions dans notre dernier Bulletin ${ }^{2}$, le décès survenu le 7 septembre 1898 et dont nous sommes en mesure aujourd'hui, grâce au journal autrichien Das Rothe Kreuz ${ }^{3}$, de retracer brièvement la carrière, était né en 1827. Dès l'année 1885 il fut élu président de la Société autrichienne de la Croix-Rouge, en remplacement du premier président de la Société, baron Charles de Tinti, et dès lors, pendant quatorze années sans interruption il dirigea les affaires de la Croix-Rouge avec une fidélité constante et un dévouement infatigable. Ce fut lui qui, déjà dans les premières années de sa présidence, mena à bien la grande ceuvre de l'organisation de la Croix-Rouge sur les bases. qu'elle a conservées jusqu'ici.

Parmi les travaux les plus importants, accomplis par lui dans ce domaine et les progrès dus à son intervention, citons entre autres : l'érection en 1885 du premier lazaret militaire de la CroixRouge autrichienne, l'organisation en 1890 des colonnes de transport de malades, l'obtention d'une franchise de port plus étendue et de diverses facilités de transport, la construction en 1897 d'un bâtiment pour la Société, l'achèvement la même année du deuxième lazaret militaire, la création en 1898 de deux nouvelles colonnes de transport de blessés, et maints autres encore, sans compter les. nombreuses instructions, directions, et manuels qui sont dus à sa plume.

Ce fut sous sa présidence que la Société autrichienne traversa les événements les plus importants de son histoire et qu'elle fut appelée, dans plusieurs grandes occasions à jouer un rôle : en 1885 , 1888 et 1890 lors des inondations en Tyrol, en Bohème, en Silésie et dans la Basse-Autriche; en 1888 par la participation à la conférence

1 Voir le portrait page ci-contre.

2 Voy. T. XXIX, p. 190.

Nos 7 et 8 de 1898 . 


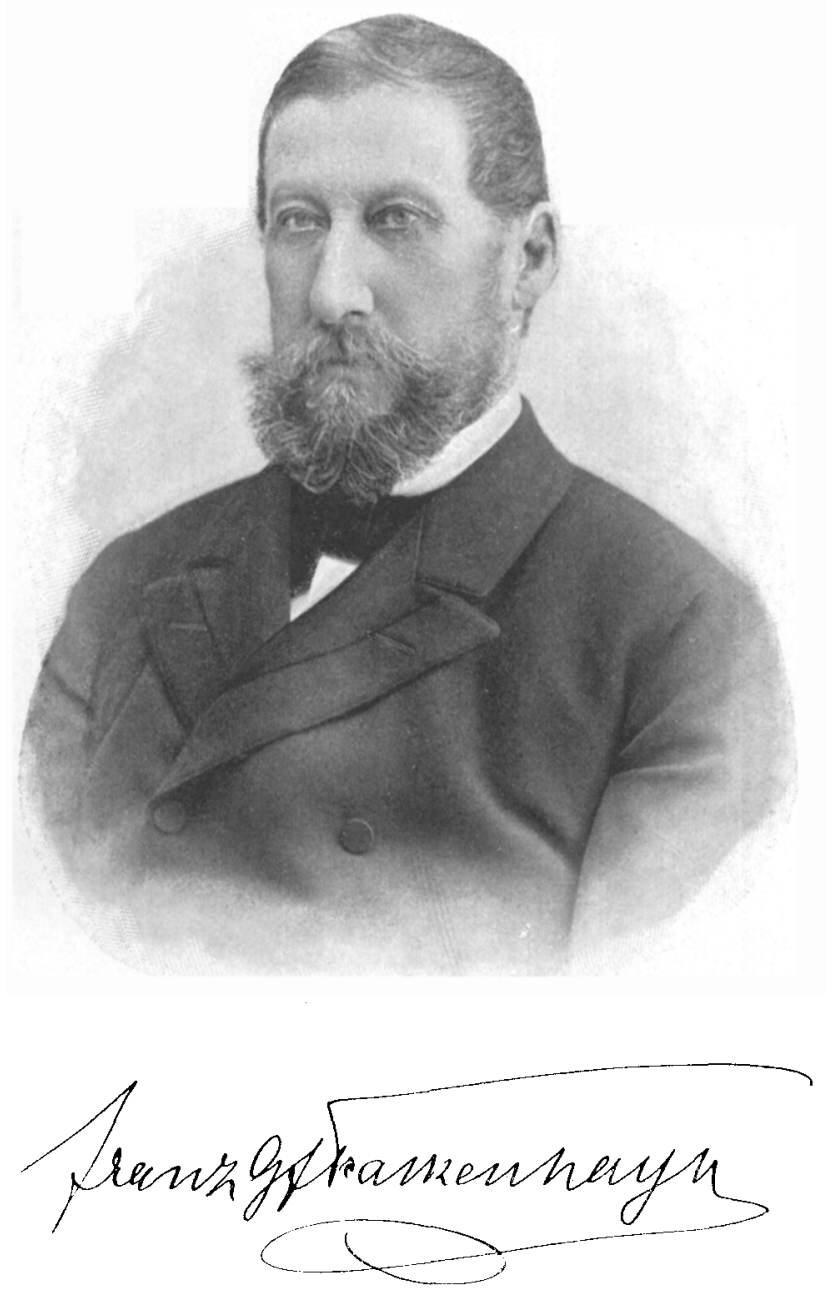

\section{M. le Comte Franz de falkenhayN}

PRESIDENT DE LA CROIX-ROUGE AUTRICHIENNI

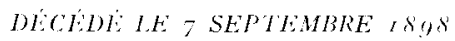


internationale de Carlsrube; en 1892, lors de l'épidémie de choléra, par l'aménagement de vingt voitures de transport pour malades et la création d'une station de désinfection à Krakau; par la participation, la même année, à la conférence de Rome; en 1895 par l'érection d'un grand hôpital de baraques, à l'époque du tremblement de terre à Laibach; par les secours envoyés en 1895 sur le champ de bataille gréco-turc; en 1897, par la réception de la VIme conférence internationale à Vienne, et dans beaucoup d'autres occasions que nous ne pouvons énumérer toutes. Aussi, à plusieurs reprises, l'archiduc Charles-Louis et l'archiduc Louis-Victor ont-ils rendu hautement hommage aux services rendus par la Croix-Rouge autrichienne et adressé un témoignage de profonde reconnaissance à la personne de son président.

Cette activité étendue, intelligente et éclairée, qui a grandement contribué à faire de la Croix-Rouge en Autriche ce qu'elle est devenue, restera dans la mémoire et dans le cœur de tous comme le plus beau souvenir de ce président regretté.

Il y a peu d'années encore, il paraissait jouir de la plénitude de ses forces physiques; aucune séance n'avait lieu sans qu'il fùt présent, malgré la distance qui séparait son château de Walpersdorf de l'endroit où elles se tenaient. Il étudiait les affaires à fond et ne prenait jamais de décision hâtive ou prématurée. Il possédait à un haut degré cette qualité précieuse chez un président, la ponctualité.

D'une intelligence rapide, il arrivait promptement à la décision que commandaient les circonstances. Par-dessus tout extrêmement modeste ; répétant toujours qu'il n'était pas orateur, il savait cependant exposer son point de vue avec une grande clarté et une parfaite précision. D'une urbanité exquise et d'une bienveillance inépuisable, il savait allier à la déférence qu'il témoignait aux opinions d'autrui la parfaite droiture et la courageuse franchise de sa nature de soldat. Ses qualités de décision furent à maintes reprises d'un grand prix pour la Société autrichienne; il savait payer de sa personne, comme il le fit bien voir à l'occasion du tremblement de terre de Laibach en se rendant lui-même immédiatement sur les lieux pour constater de visu ce qu'il y avait à faire. On pourrait, dans sa vie, trouver bien des exemples de cette promptitude d'action et de ce dévouement, qui faisaient que les événements les plus imprévus ne le déconcertaient jamais et ne le prenaient jamais au dépourvu.

On se souvient de la manière distinguée dont il présida la 
VI ${ }^{\text {me }}$ conférence internationale des Sociétés de la Croix-Rouge à Vienne, faisant toujours preuve de tact, d'urbanité et de décision. Il était déjà, à cette époque, gravement ébranlé dans sa santé, mais la maladie ne l'arrètait pas, et le reproche que pouvaient lui faire ses amis tótait de ne pas se ménager : ce fut l'enthousiasme pour la noble cause de la Croix-Rouge qui le soutint jusqu'à la fin et lui permit d'être jusqu'au bout pleinement à la hauteur de sa grande tâche.

Nous souhaitons, avec l'auteur de l'artic'e que nous analysons, que son départ et le vide immense qui en résultera au sein de la Croix-Rouge autrichienne ne porte en rien atteinte à la prospérité et au bon renom de cette société.

Ajoutons pour terminer, sur le rôle qu'il a joué en dehors de la Croix-Rouge, quelques brèves indications qui nous sont fournies par un membre de sa famille. Né à Vienne, il y fit ses études de droit jusqu'en l'année 1848 , où la révolution le força à les interrompre et le poussa à se faire enrôler. Depuis lors, il prit part à toutes les campagnes avec l'armée de son pays, en Hongrie, en Italie, en Bohême. Il quitta le service après la guerre de $1866 \mathrm{et}$ se consacra à l'administration de ses biens et à des œuvres philanthropiques. Quoique très conservateur et foncièrement catholique, il sut rapidement se conquérir l'estime universelle; il ful pendant longtemps chef du parti conservateur à la Chambre des Pairs, et président d'un grand nombre de sociétés patriotiques, catholiques et agricoles. Mais ses longs services dans l'armée le rendaient particulièrement apte à remplir ses fonctions de président de la Croix-Rouge autrichienne, qui absorbèrent bientôt ses forces et constituèrent le plus grand intérêt de sa vie.

En récompense de ses services, l'empereur le nomma successivement conseiller intime, grand croix de l'Ordre de la Couronne de Fer et chevalier de l'Ordre de la Toison d'Or.

La foule considérable qui a tenu à lui rendre les derniers hommages le 12 septembre dernier, jour de son ensevelissement, a été un vivant témoignage du respect et de l'affection dont il était entouré non seulement par ses amis et parents, mais par la population tout entière. 